\title{
NOVICE DRIVER SIMULATION TRAINING POTENTIAL FOR IMPROVING HAZARD PERCEPTION AND SELF-CONFIDENCE WHILE LOWERING SPEEDING RISK ATTITUDES FOR YOUNG MALES
}

\author{
George D. Park, R. Wade Allen, Theodore J. Rosenthal \\ Systems Technology, Inc. \\ Hawthorne, CA, USA \\ george.park@systemstech.com
}

\begin{abstract}
Summary: Despite the potential for improving hazard perception skills, novice driver training interventions run the risk of student overestimations in driving skills and increased risk-taking, e.g., speeding-particularly for young male drivers. Provided is the simulator performance and survey (driver self-confidence and speeding risk attitude) data of simulator trained and no-trained students from a high school driver education intervention, $N=316$. Multivariate analysis of simulator performance measures and survey results at pre/post-test showed that simulator trained drivers had better hazard perception and higher driver self-confidence than no-trained drivers at semester end. While no strong sex differences were found for driving performance, males showed higher self-confidence and speed risk attitudes. Females lowered their speed risk attitudes regardless of training group. However, only simulator trained males lowered their speeding attitude while no-trained males showed no change. Driving simulation training that provides repeated collision events may help novice male drivers in particular by mediating the effects of over self-confidence from driving skill acquisition programs.
\end{abstract}

\section{INTRODUCTION}

Over the years, a variety of novice driver training programs have been developed to improve the hazard perception ability of beginning drivers by using driving simulation scenarios that expose students to hazardous situations requiring a real-time response (Allen, Park, \& Cook, 2008; Ivancic \& Hesketh, 2000; Wang, Zhang, \& Salvendy, 2010). While competency in hazard recognition and response is certainly a prerequisite for avoiding crashes; skill-based, driver training can lead to unintended negative consequences. Over-estimations of skill by novice drivers may potentially increase exposure to hazardous situations, negating any training advantages (Mayhew \& Simpson, 2002). Young male drivers in particular, are more likely to overestimate their own driving competency, perceive less risks in dangerous driving situations (DeJoy, 1992) and make more voluntary decisions to increase risks like speeding (Clarke, Ward, \& Truman, 2005; Moller \& Haustein, 2014; Whissell \& Bigelow, 2003). As such, any novice driver program focusing on improving skill acquisitions (e.g., hazard perception and response) needs to be aware of potential inflations in driver self-confidence and the risk-taking attitudes and behaviors that may follow. Previous driver training studies have shown that certain skills such as hazard perception/anticipation can lead to a decrease in risk-taking behaviors, e.g., speeding (McKenna, Horswill, \& Alexander, 2006).

The purpose of this paper is to demonstrate the potential of driver simulation training to improve hazard perception skill while mediating the novice male driver's propensity for speeding risk. The training system utilized was the Driver Assessment and Training System (DATS). DATS is a computer-based instructional system that uses both multimedia and driving simulation for 
driver education applications. Designed to complement traditional, classroom-based teaching, it focuses on hazard perception and response. The curriculum comprises of eight sessions ( $\sim 10-20$ min each) with first and last sessions used for orientation, pre/post test drives, and survey. Training lessons are organized according to vehicle speed environments: low-speed residential, mid-speed urban and high-speed rural. Scenarios are progressively more challenging in terms of hazard count, timing due to speed environment, and scene complexity. Multimedia materials total $\sim 24$ min and 12 training scenarios total $\sim 75$ min of simulation time. The user-interface automates presentation of driving scenarios, videos, slides, quizzes, survey, and performance results (Allen, Park, Terrace, \& Grant, 2011; Terrace, Park, \& Allen, 2010). To study the training potential of the DATS program, it was implemented in a high school driver's education program in the 2013 fall semester (Figure 1). Fifteen classroom periods were assigned to either the simulator training ( 9 classrooms) or no-training ( 6 classrooms) group. Only the simulator training group was provided the full DATS curriculum. Both groups were provided pre/post-test drives and surveys at the beginning and end of the semester. Hazard perception performance was measured with simulator performance for: collision avoidance accuracy, intersection violations, speed limit exceedances, and driver lane crossings. Survey methods were used to generate composite scores for driver self-confidence and speeding risk attitudes.

\section{METHODS}

\section{Participants}

The data from 316 students (169 males, $M_{\text {age }}=15.4 \mathrm{yr}$, age range $=15$ $17 \mathrm{yr}$., $89 \%$ in $10^{\text {th }}$ grade; pre-learner's permit) from the driver's education program at Livingston HS, New Jersey, is presented. This study was IRB approved and informed parental consent was obtained. Students in the
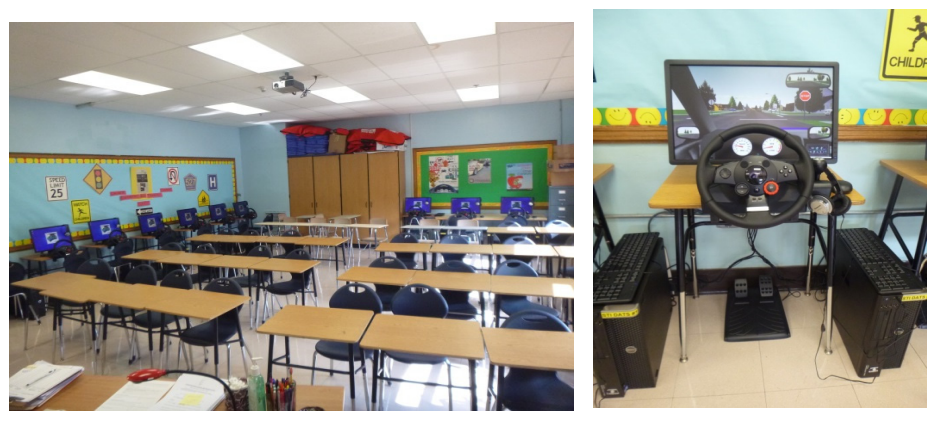

Figure 1. DATS 10 station setup in LHS driver education classroom and a single DATS simulator configuration no-training group were given the opportunity to use DATS once data collection was completed.

\section{Pre/Post-Test Scenario Drives}

Pre/post-test scenario drives were designed to appear as different as possible using visual simulation elements (e.g., far horizon, building models, ground textures, etc.) while still retaining critical testing elements. Drives were designed with a counterbalanced number of intersections (9), turn instructions ( 1 right, 1 left), signal lights (2 green, 1 amber), 4-way stop signs (4), speed limit zones $(20,25,45$, and 40-70 $\mathrm{mph}$; delta $3 \mathrm{mph}$ ), traffic environments (school, residential, urban, and rural), pedestrian collision events (5), vehicle collision events (3), and drive time ( $\sim 8$ min). Collision events presented with the same spatial (e.g., originating from left or right) design and event triggering - based on driver vehicle to collision object distance. No auditory/visual feedback (e.g., crash noises) was provided to drivers for poor/incorrect performance (e.g., collisions, missed stop signs) to reduce artificial increases in driver vigilance and maintain the integrity of the driver's behavior.

\section{Survey Materials}

The driving self-confidence score was the summation of 9 questions (7- and 4-point rating scales; total score range: 9-36 pts.) developed by the authors (Table 1). Higher scores indicate 
higher self-confidence in driving ability. The speeding risk attitude score was the summation of 10 questions (4-point rating scale; total score range: 10-40 pts.) taken from the Young Driver Attitude Scale (YDAS), developed by the AAA Foundation for Traffic Safety (Malfetti, Rose, DeKorp, \& Basch, 1990). Higher scores indicate higher speeding risk attitude.

Table 1. Pre/post survey questions measuring driving self-confidence and speeding risk attitude

\begin{tabular}{|c|c|c|}
\hline Category & Survey Question & Answer Type \\
\hline \multirow{9}{*}{$\begin{array}{l}\text { Driving } \\
\text { Self- } \\
\text { Confidence }\end{array}$} & Rate your current driving abilities compared to the rest of the driving population. & A \\
\hline & Rate your current driving abilities with other student drivers your age. & A \\
\hline & How confident are you in your driving skills to avoid a crash? & $\mathrm{B}$ \\
\hline & A driver should always be able to avoid a crash no matter the situation. & $\mathrm{C}^{*}$ \\
\hline & Driving like any other skill can be mastered. & $\mathrm{C}^{*}$ \\
\hline & If you pay enough attention, it's OK to eat or drink something while driving. & $\mathrm{C}^{*}$ \\
\hline & If I took the DMV behind-the-wheel test today, I would pass. & $\mathrm{C}^{*}$ \\
\hline & $\begin{array}{l}\text { The odds are very low that I will get into an accident my first year of driving with a } \\
\text { license. }\end{array}$ & $\mathrm{C}^{*}$ \\
\hline & There are a lot of driving situations that I am scared of. & $\mathrm{C}$ \\
\hline \multirow{10}{*}{$\begin{array}{l}\text { Speeding } \\
\text { Risk } \\
\text { Attitude }\end{array}$} & You've got to be an idiot to race when driving. & $\mathrm{C}$ \\
\hline & If you have good skills, speeding is OK. & $\mathrm{C}^{*}$ \\
\hline & I usually (or will usually) drive faster when my friends are in the car. & $\mathrm{C}^{*}$ \\
\hline & Cops watch for speeders so that they can reach their quota of tickets and collect fines. & $\mathrm{C}^{*}$ \\
\hline & It is fun to drive fast. & $\mathrm{C}^{*}$ \\
\hline & Just because you don't get caught speeding doesn't make it right. & $\mathrm{C}$ \\
\hline & It's OK to speed if you have a radar detector and can get away with it. & $\mathrm{C}^{*}$ \\
\hline & Driving 5 or $10 \mathrm{mph}$ above the speed limit is OK because everyone does it. & $\mathrm{C}^{*}$ \\
\hline & I think it's OK to speed if traffic conditions allow you to do so. & $\mathrm{C}^{*}$ \\
\hline & I like (or will like) to show off my skill by driving fast. & $\mathrm{C}^{*}$ \\
\hline \multicolumn{2}{|c|}{$\begin{array}{l}\text { A: } 7 \text {-pt scale: } 1=\text { very poor, } 4=\text { average, } 7=\text { expert } \\
\text { scored } \\
\text { B: } 7 \text {-pt scale: } 1=\text { very little confidence, } 4=\text { confident, } 7=\text { very confident } \\
\text { C: } 4 \text {-pt scale: } 1=\text { strongly agree, } 2=\text { agree, } 3=\text { disagree, } 4=\text { strongly disagree }\end{array}$} & $*=$ reverse \\
\hline
\end{tabular}

\section{Procedure}

Participants began with a demographic survey followed by driving self-confidence and speed risk attitude questions, which were randomly sorted. Students were then given an orientation slideshow and drive. The pre-test drive was then presented, concluding the first session. The simulator training group then completed the remaining 6 training sessions ( $\sim 1$ per week). When finished, both groups then completed the post-test drive followed by the same survey. The notraining group was given the orientation drive again prior to post-test.

\section{RESULTS}

\section{Pre/Post-Test Simulator Performance}

Thirteen participants (4\%) were removed due to performance variables (e.g., vehicle speed, runtime, collision counts, and vehicle control indicators) that indicated outlier behaviors beyond 2x's median interquartile range. The remaining analysis sample included 303 students: 162 males, $M_{\text {age }}=15.4 \mathrm{yr}$, age range $=15-17 \mathrm{yr}$., simulator group $=171$, no-training group $=132$. A training group (2: simulator training, no-training) $\mathrm{x} \operatorname{sex}(2$ : male, female) $\mathrm{x}$ test drive (2: pre, post) mixed design MANOVA, $n=303, a=.05$, was conducted for driving performance as comprised by the measures: 1) collision avoidance accuracy: \% of collision events avoided, 8 in pre-test and 9 in post-test, 2) intersection violations: stop sign and signal light violations, 3) speed exceedances: times over posted limit, and 4) lane crossings: driver lane's road edge and centerline crossing counts. To meet the assumption of homogeneity of covariance matrices, 
square root transformations were performed for intersection violations, speed exceedances, and driver lane crossings. Mean $(S E)$ values for these measures are reported using untransformed values for easier data interpretation.

Training Group Differences. A training group x test drive interaction was found, Pillai's Trace = $.173, F(4,296)=15.45, p<.001$, suggesting that training groups differed in driving performance across the pre/post-test drives. Subsequent ANOVAs showed sig. interactions for all measures: collision avoidance $(p<.001)$, intersection violations $(p<.001)$, speed exceedances $(p=.003)$, and lane crossings $(p=.003)$. Main effects were also found for training group, Pillai's Trace $=$ $.091, F(4,296)=7.45, p<.001$, and test drive, Pillai's Trace $=.593, F(4,296)=107.84, p<.001$. Follow-up t-test results indicated that at pre-test, no training group differences were observed. At post-test; however, simulator trained students provided higher collision avoidance accuracy, fewer intersection violations, fewer speed exceedances, and fewer lane crossings (Figure 2). Paired t-tests indicated that by the end of school semester, both training groups improved in collision avoidance accuracy $(p<.001)$, had fewer intersection violations $(p<.001)$, and speed limit exceedances $(p<.001)$. For driver lane crossings, no change was found for the simulator training group at the post-test drive $(p=.332)$, while for the no-training group, higher driver lane crossings were found $(p=.003)$.

Sex Differences. A sex x test drive interaction was found, Pillai's Trace $=.057, F(4,296)=4.48$, $p=.002$, suggesting that males and females differed in driving performance across pre/post-test drives. However, subsequent ANOVAs found a sig. interaction for only driver lane crossings ( $p$ $<.001)$. Follow-up t-tests for lane crossing indicated that during the pre-test drive, females had more road edge and centerline crossings $(M=9.35, S E=.31)$ than males $(M=7.12, S E=.25), p$ $<.001$; at post-test, no sex difference was observed. A main effect was also found for gender, Pillai's Trace $=.085, F(4,296)=6.84, p<.001$, with subsequent ANOVAs showing main effects for intersection violations $(p=.004)$ and lane crossings $(p<.001)$. Females on average had more intersection violations and lane crossings than male students. Of note, no overall sex differences were found in regards to collision avoidance accuracy or speeding behaviors.

\section{Pre/Post-Test Survey}

A training group (2: simulator training, no training) $\mathrm{x} \operatorname{sex}(2$ : male, female) $\mathrm{x}$ test drive (2: pre, post) mixed design ANOVA was performed for the composite survey scores for driving selfconfidence and speed risk attitude questions, $n=316, \alpha=.05$.

Driver Self-Confidence. As expected, males on average provided higher driving self-confidence scores $(M=22.7, S E=.2)$ than females $(M=20.4, S E=.2) ; F(1,312)=50.92, p<.001, \eta_{\mathrm{p}}{ }^{2}=$ .140. Higher driving self-confidence was also found by the end of semester $(M=22.6, S E=.2)$ relative to the beginning $(M=20.5, S E=.2) ; F(1,312)=178.07, p<.001, \eta_{\mathrm{p}}{ }^{2}=.363$. Of note, a training group $\mathrm{x}$ test drive interaction was found, $F(1,312)=7.82, p=.006, \eta_{\mathrm{p}}{ }^{2}=.024$. Results suggest no training group differences at pre-test. At post-test; however, both male and female students in the simulator training group had higher self-reported driving confidence compared to the no training group, $t(314)=2.65, p=.008$ (Figure 3).

Speeding Risk Attitude. Consistent with prior research, males on average provided higher speeding risk attitude scores $(M=20.1, S E=.3)$ than females $(M=18.0, S E=.3) ; F(1,312)=$ 

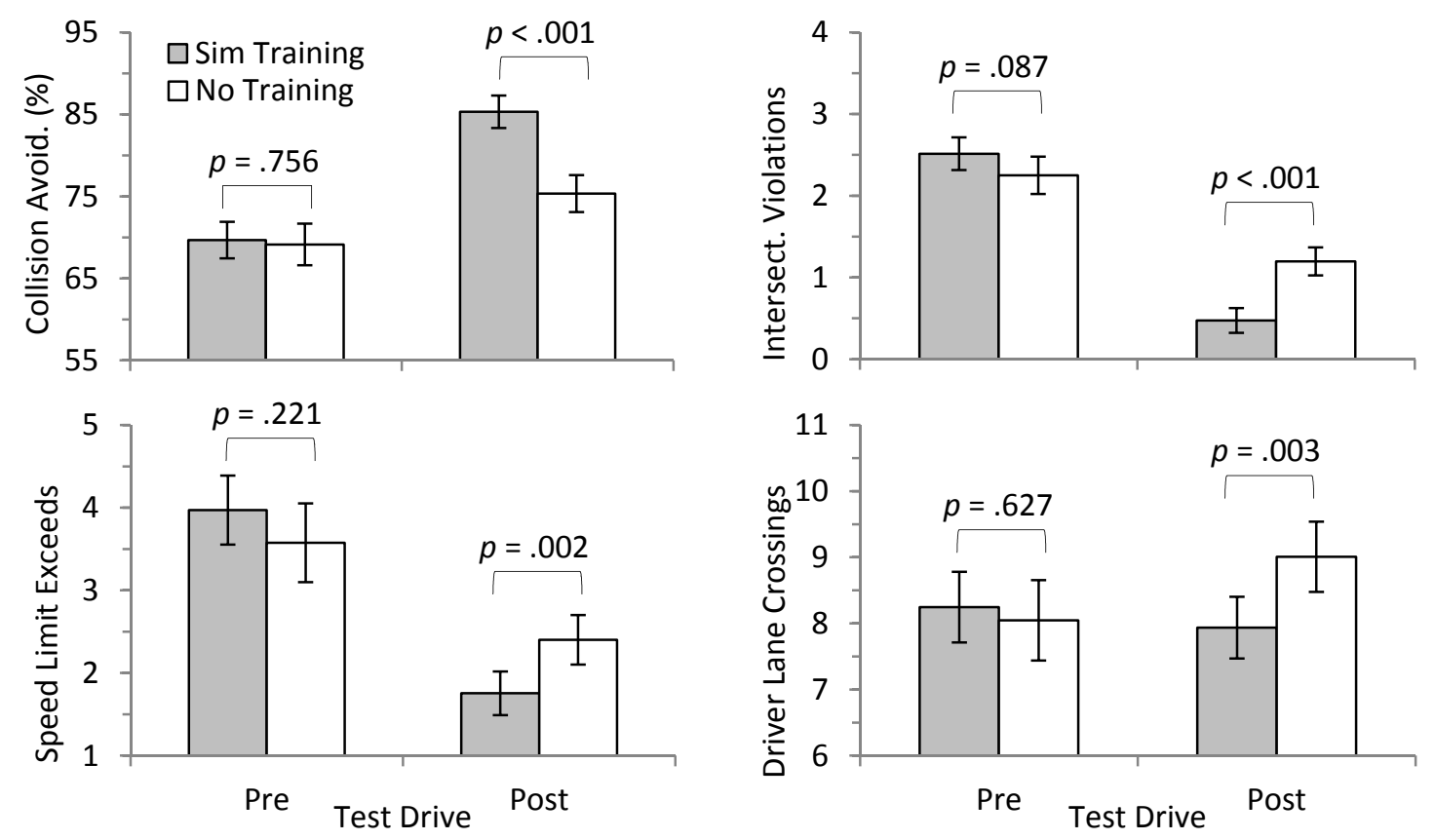

Figure 2. Mean values with $95 \%$ CIs by training group and test drive for driving simulator performance measures. P-values for 2-sample t-tests provided

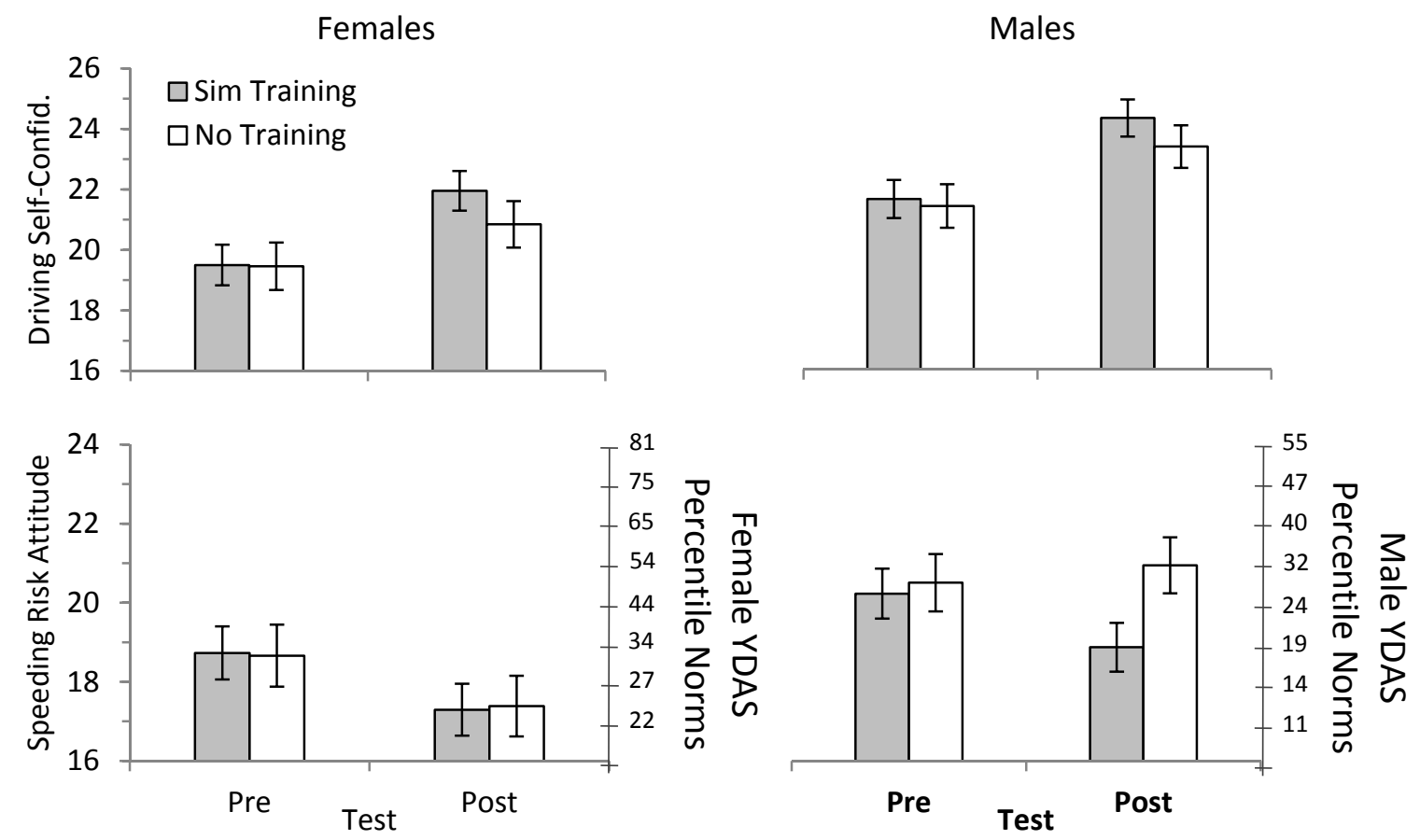

Figure 3. Average composite survey scores with $95 \%$ CIs by sex and training group for driving selfconfidence and speeding risk attitudes. Female/male percentile norms from YDAS (Young Driver Attitude Scale, AAA Foundation for Traffic Safety) provided for speeding risk attitude values

$25.30, p<.001, \eta_{\mathrm{p}}^{2}=.075$. However, percentile norms indicated that both sexes fell within the $40^{\text {th }}$ percentile rank. Lower scores were also found by the end of the semester $(M=18.6, S E=.3)$ relative to the beginning $(M=19.5, S E=.2) ; F(1,312)=21.43, p<.001, \eta_{\mathrm{p}}{ }^{2}=.064$. 
More importantly, a 3-way interaction was found, $F(1,312)=25.59, p=.038, \eta_{\mathrm{p}}{ }^{2}=.014$, suggesting that 2-way interaction patterns of training groups across test drive differed depending on sex (Figure 3). Females on average, regardless of simulator training, provided lower speeding risk attitudes at the end of the semester, $t(146)=6.16, p<.001$. For males; however, nonsimulator trained males showed no change in speeding risk attitudes despite a semester of traditional classroom instruction. In contrast, simulator trained males lowered their speeding attitudes at the time of post-test, $t(96)=3.42, p=.001$. Two-way interactions were also found for training group $\mathrm{x}$ test drive, $F(1,312)=6.22, p=.013, \eta_{\mathrm{p}}{ }^{2}=.020$, and gender $\mathrm{x}$ test drive, $F(1,312)=5.25, p=.023, \eta_{\mathrm{p}}{ }^{2}=.017$. But these interactions were not relevant in light of the 3way interaction.

\section{DISCUSSION}

Simulator performance results suggest that DATS and comparable simulator training interventions have the potential to improve a driver's hazard perception and response. At the beginning of the semester, no simulator performance differences between the training groups were found. While both groups showed improvement by the end of the semester, simulator trained students provided better collision avoidance, fewer intersection violations, fewer speed exceedances, and fewer driver lane crossings compared to the no-training group. Although not confirmed by specific collision event analysis, fewer driver lane crossing results could suggest that simulator trained drivers were able to anticipate hazards and respond by slowing their vehicle speed as opposed to evasive maneuvering out of the driver's lane. Surveys results suggest that simulator training has the potential to improve a student's self-perception of their driving ability, while also reducing risk-taking attitudes in speeding, particularly for young male drivers. For simulator trained students, increases in driver self-confidence did not necessarily result in increases in speeding risk attitudes for either sex. A plausible reason for this is that the simulator training scenarios allowed students to experience collision hazards in real-time as it related to their vehicle speeds and driving environment, which in turn mediated their speeding risk attitudes. Survey results were also consistent with prior studies-young male drivers relative to their female counterparts tend to overestimate their driving skill and have higher speeding risk attitudes. These attitudes were observed despite the fact that no sex differences were found in driving performance for collision avoidance accuracy or speed exceedances. It is unclear, however; whether or not simulator trained male students were dangerously over-estimating their skill levels relative to their control group peers. Furthermore, the results beg the question: Is higher self-confidence from training still a negative if it does not lead to risk-taking behaviors? Without behind-the-wheel data, it also remains unclear if our simulator performance results reflect the simulator trained group simply becoming adept at the driving simulator itself or if hazard perception ability will transfer to real-world driving. Similarly, it is unknown if the speeding risk attitudes of simulator trained, young males will persist once licensure and time behind-the-wheel accrues. However, previous studies have shown that simulator performance may have predictive ability for pre-licensed, novice drivers in regards to traffic violations (de Winter, 2013). As such, our study results are encouraging for future novice driver training applications and warrants future research with continued driver attitude monitoring methods.

\section{ACKNOWLEDGMENTS}

Systems Technology, Inc. is a privately-owned company that manufactures and distributes the STISIM Driving Simulator used in this study. This study was funded by the National Center for 
Injury Prevention \& Control (Grant No. 5R44CE001492-03). Special thanks to Nancy Ooms, Tamara Floruss, Michael Munley, and Andrew Krupa from Livingston High School.

\section{REFERENCES}

Allen, R. W., Park, G. D., \& Cook, L. M. (2008). The effect of simulation training on novice driver accident rates. In L. Dorn (Ed.), Driver Behaviour and Training (Vol. III). Burlington, VT: Ashgate Pub. Co.

Allen, R. W., Park, G. D., Terrace, S., \& Grant, J. K. (2011). Detecting transfer of training through simulator scenario design: A novice driver training study. Paper presented at the 6th International Driving Symposium on Human Factors in Driver Assessment, Training and Vehicle Design, Lake Tahoe, CA.

Clarke, D. D., Ward, P., \& Truman, W. (2005). Voluntary risk taking and skill deficits in young driver accidents in the UK. Accident Analysis and Prevention, 37(3), 523-529. doi: 10.1016/j.aap.2005.01.007

de Winter, J. C. (2013). Predicting self-reported violations among novice license drivers using pre-license simulator measures. Accident Analysis and Prevention, 52, 71-79. doi: 10.1016/j.aap.2012.12.018

DeJoy, D. M. (1992). An examination of gender differences in traffic accident risk perception. Accident Analysis and Prevention, 24(3), 237-246.

Ivancic, K., \& Hesketh, B. (2000). Learning from errors in a driving simulation: Effects on driving skill and self-confidence. Ergonomics, 43(12), 1966-1984.

Malfetti, J. L., Rose, P., DeKorp, N., \& Basch, C. (1990). Manual for the Administration of the Young Driver Attitude Scale, an Instrument to Measure Young Driver Risk-taking Attitudes.

Mayhew, D. R., \& Simpson, H. M. (2002). The safety value of driver education and training. Injury Prevention, 8, 3-7.

McKenna, F. P., Horswill, M. S., \& Alexander, J. L. (2006). Does anticipation training affect drivers' risk taking? Journal of Experimental Psychology-Applied, 12(1), 1-10. doi: 10.1037/1076-898x.12.1.1

Moller, M., \& Haustein, S. (2014). Peer influence on speeding behaviour among male drivers aged 18 and 28. Accid Anal Prev, 64, 92-99. doi: 10.1016/j.aap.2013.11.009

Terrace, S., Park, G. D., \& Allen, R. W. (2010, July). A novice driver training system. Paper presented at the Image 2010, Scottsdale, AZ.

Wang, Y. B., Zhang, W., \& Salvendy, G. (2010). Effects of a simulation-based training intervention on novice drivers' hazard handling performance. Traffic Injury Prevention, 11(1), 16-24. doi: 10.1080/15389580903390631

Whissell, R. W., \& Bigelow, B. J. (2003). The speeding attitude scale and the role of sensation seeking in profiling young drivers at risk. Risk Anal, 23(4), 811-820. 